\title{
Parental diary of infant cry and fuss behaviour
}

\author{
R G BARR, ${ }^{*}$ M S KRAMER, ${ }^{*} \dagger$ C BOISJOLY, L McVEY-WHITE, AND I B PLESS $\dagger^{*}$ \\ Departments of *Paediatrics, and + Epidemiology and Biostatistics, McGill University Faculty of Medicine, \\ Montreal, Canada
}

SUMMARY Despite their common use parental diaries of infants' cry and fuss behaviour have not been compared with objective methods of recording. To understand what is meant by the descriptions of crying and fussing in the diaries, the diaries of 10 mothers of 6 week old infants were compared with tape recordings of vocalisations made by the babies over a 24 hour period. There were moderately strong correlations between the frequency of episodes (clusters of 'negative vocalisations') on the audiotape and episodes of 'crying and fussing' in the diaries, and between the duration of episodes on the audiotape and episodes of 'crying' in the diaries. To assess the acceptability of the diaries for recording information for clinical and epidemiological research, they were then used in a population study of a wide socioeconomic group. Usable data were obtained from $91 \%$ of the sample. The results suggest that despite pronounced differences between recording methods, these diaries may provide valid and useful reports of crying and fussing in the short term.

Parental recording has commonly been used to describe emerging patterns of infant behaviour, and has a potential for use in the clinical assessment of behavioural problems. Most of our knowledge about infants' crying after the neonatal period is derived from studies that used diaries, despite the recognised potential of over or under reporting. ${ }^{1-4}$ Data from diaries, ${ }^{1-4}$ tape recordings, ${ }^{5}$ parental recall, ${ }^{6}$ and direct observations ${ }^{7}$ have all shown that the amount of crying tends to increase until about 6 weeks of age and then gradually decreases, and that within a 24 hour period crying occurs more often in the evening; this implies that diary reporting is reasonably accurate. We are not aware, however, of any data that directly compare parental recordings with a recording system less susceptible to bias. As a result, we know little about how parent recording represents the infant vocalisations which are part of the crying behaviour.

The diaries used in this study were designed to be easy to use and to be suitable for a diverse sample of the population. We first compared them with 24 hour audiotape recordings of the infants' vocalisations. Crying refers to a complex act that includes elements of movement, facial expression, and voice, and is usually interpreted as expressing a negative emotion. In the tape recordings the vocal part of crying is designated as negative vocalisation compared with neutral sounds (such as grunting) and positive sounds (such as cooing).
Secondly, the sociodemographic characteristics of parents who returned diaries with readable data were compared with those of parents who did not from a population sample in a prospective cohort study. Thus the findings describe quantitative associations between negative vocalisations and the diary records of crying and fussing, they illustrate the limitations of both techniques in assessing the amount of infant crying, and they indicate the potential limits on the use of diaries for this purpose in the general population.

\section{Subjects and methods}

Ten mothers (who spoke fluent English or French) of normal 6 week old infants, who were in the nursery of a large general hospital associated with the university or a community health unit volunteered to take part in the comparison of diaries and tape recordings. The mean age of the infants was $6 \cdot 3$ weeks (range 5.5-7) at the time of recording; there were five boys and five girls, and seven were exclusively breast fed. The mean (SD) socioeconomic score measured by Green's two factor index ${ }^{8}$ was $67.8(11.7)$, a wide range that is typical of this community. ${ }^{9}$ Informed consent was obtained before the tape recordings were made.

PARENTAL DIARIES

Fig 1 shows the format of the diaries; this was the 
Please mark behaviour patterns as indicated:

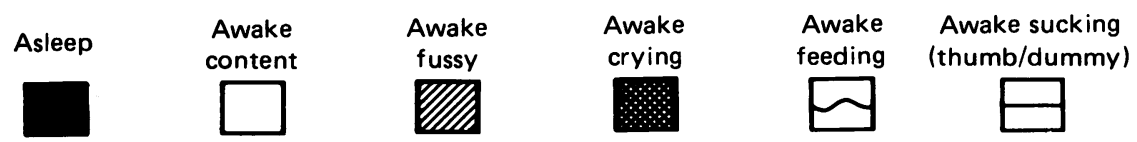

Please mark type of feeding given, above the line, as follows: 'bottle' or 'breast'

Please mark cries of less than one minute, above the line as follows: ' $\checkmark$ '

Please mark bowel movements, when discovered, below the line as follows: ' $l$ '

Example:

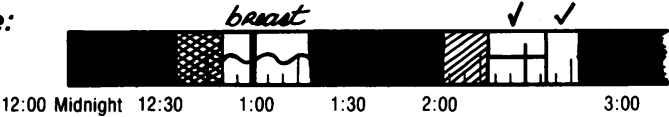

Night

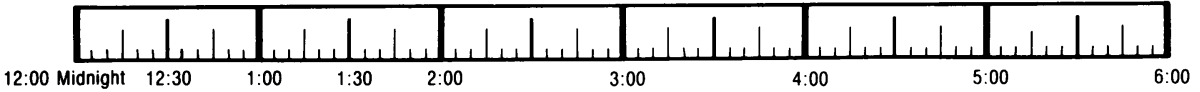

Morning
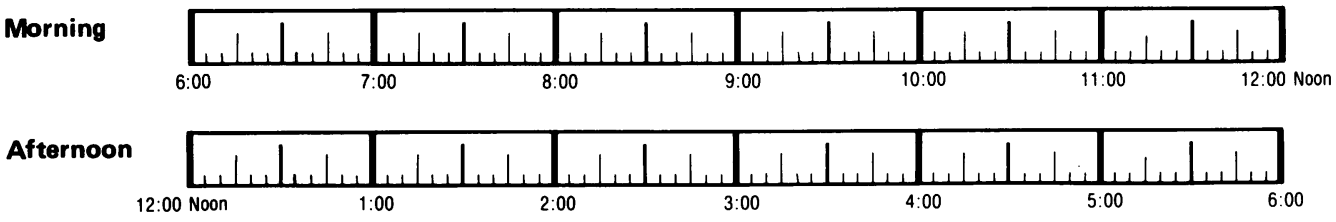

Evening

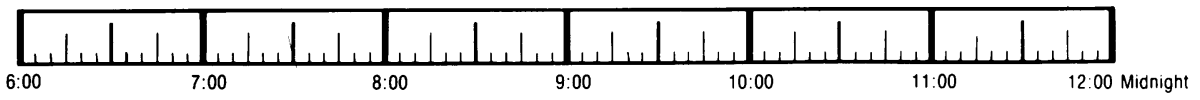

This was a typical day

$\square$ This was not a typical day, because

Fig 1 Example of diary; Four 'time rulers' each representing six hours are included on each page and vertical lines indicate five minute intervals.

result of extensive pilot studies among mothers of normal children. 'Time rulers' were filled in using symbols representing six behaviour patternssleeping, awake and content, fussing, crying, feeding, and sucking. The smallest unit of time that could be recorded was five minutes. To make them easy to use the symbols were designed to have definite start and end points and to need a minimum of explanation of the behaviour pattern to which they referred. To distinguish short, acute cries the symbol ' $V=$ crying for less than one minute' was printed above the time rulers. Considerable inconsistency was noted in the use of this symbol, however, as many parents disregarded it and so it was subsequently ignored. In addition, parents were asked to indicate the type of feeding (breast or bottle), the time of recognition of a bowel movement, periods not in contact with the infant, and any unusual occurrences during the day.

Diaries were available in English and French and to ensure that they meant the same in each language they were translated from English to French and then back from French to English, and then checked for ambiguity.

Showing the mother how to use the diary seldom took longer than five minutes. It was emphasised that all behaviour was to be coded by one of the available symbols. Mothers were questioned to be sure that they understood the temporal subdivisions of the time ruler. The only definition that was provided was for the category of 'fussing'. This had been added at the request of parents who wanted a symbol to cover behaviour that was 'not quite crying but not awake and content either'. All the other categories of behaviour were assumed to be self evident. Parents were told that diaries should be filled in when convenient and that they were not to disrupt their daily activities. They were not told how often to record.

RECORDING OF VOCALISATIONS MADE BY INFANTS Rebelsky and Black used a voice activator circuit 
when recording vocalisations made by infants from fixed microphones attached to the $\cot ^{510}$ and other workers used telemetric techniques in adults, ${ }^{11} 12$ adolescents, ${ }^{13}$ and children. ${ }^{14-17}$ In this study the tape recordings were made using a voice activated recording system that combined the advantages of radiotelemetry (freedom of movement) and a voice activator circuit. The system allowed continuous 24 hour recordings to be made with simultaneous recording of a time code on a second channel. It comprised a small microphone and radiotransmitter (weighing $42 \mathrm{~g}$ ) fitted into a light cotton shirt so that the microphone could be placed about $7 \mathrm{~cm}$ from the infant's mouth. A thin wire aerial hung loosely at the side with the distal end tucked under the nappy. The transmitter was powered by two 1.5 volt batteries and was switched on continuously throughout a recording session. The vocalisations made by the infant, and other sounds picked up by the microphone, were relayed to a frequency modulated receiver, and then through a control panel to a UHER 4400 JC tape recorder. The control panel incorporated a voice activator circuit that automatically turned on the tape recorder and then turned it off after seven to 10 seconds of silence. On the second channel pulses from a time generator were registered at five second intervals whenever the recorder was on. The receiver was adjusted so that all vocalisations made by the infant were recorded, as were all other sounds that exceeded that threshold. The tape ran at a speed of $6 \mathrm{~cm} / \mathrm{second}$. A 24 hour continuous monitoring session usually produced from one to three hours of recording.

\section{RECORDING PROTOCOL}

The parents were not responsible for the functioning of the system, which was already connected and housed in a wooden box $62 \times 32 \times 23 \mathrm{~cm}$ placed centrally in a convenient location. The microphone and transmitter were put into the shirt by the research assistant. The parents were instructed to put the shirt beside the infant while the nappy was being changed. The sensitivity of the transmission was determined in response to the vocalisations the infant made, and its quality was checked from all relevant rooms. Once the system was in use, the diary was reviewed. The study was described as the collection of information on the behaviour patterns of normal infants. The parents were told that the tape recorder was an easy way to record the sounds made by the infant for 24 hours without disrupting the family's routine.

\section{TRANSCRIPTION}

Sounds on the tape were categorised as 'negative vocalisations', 'non-negative vocalisations', parents' vocalisations, and other sounds-for example, sheets rustling and the noise of the vacuum cleaner. A distinctive 'zeep' sound indicated that the tape had been activated so that the beginning and end of each recorded period could easily be distinguished. The time signal was shown on a digital clock, and at least one time marker was shown each time the tape was activated. By listening to the playback the presence, time, and duration of each sound could be indicated sequentially on a transcription sheet. All tapes were transcribed by a single observer, and only the infant's negative vocalisations were transcribed. Four randomly selected tapes were retranscribed and intraobserver reliability was determined separately for transcribing the frequency (events in 24 hours) and duration (seconds in 24 hours) of negative vocalisations $(r>+0.99$ for both, Pearson's product moment coefficient). Events lasting less than five seconds (usually one to two seconds) accounted for $47 \%$ of the frequency but only $7 \%$ of the total duration of negative vocalisations.

EDITING, REDUCTION, AND ANALYSIS OF DATA It was apparent from studying the transcripts of the tape recordings that negative vocalisations tended to cluster together, being separated by long periods of silence, as might be expected from direct observation of crying and fussing in the infants. It was assumed that the crying or fussing symbols used in the diary represented these clusters, referred to as 'episodes.' Within these, episodes, however, the actual vocalisations are not continuous, but are punctuated by inspirations and spontaneous pauses. Because the omission of the ' $V$ ' symbol from the diary and the absence of negative vocalisations of less than five seconds duration from the tape recording should not affect the reporting of the prolonged clusters of crying that were of primary interest, the diaries and tape recordings were first edited to eliminate these. The edited versions are the unreduced sets of data concerning the events of crying and fussing recorded in the diaries and negative vocalisations recorded on the tapes.

The data were then processed to obtain reduced sets of data. The smallest unit of recording in the diary is five minutes (the smallest subdivision on the time ruler) (fig 1). To identify clusters that the parents might have recorded as a crying episode, while eliminating short, isolated vocalisations, the following 'grouping and elimination' rules were applied to the unreduced sets of data (fig 2): two or more events separated from each other for five minutes or less were counted as one episode; the duration of crying for an episode was the arithmetic sum of the recorded negative vocalisations within the defined episode; after the application of the first 
Example:

Raw data

(Events)

\begin{abstract}
Reduced data Frequency (Episodes)
\end{abstract}

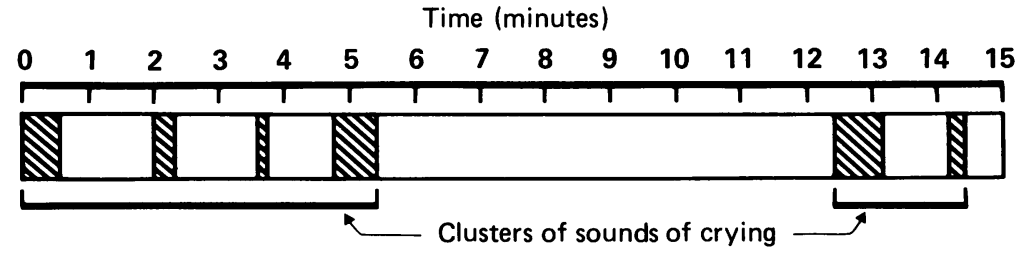

Time (minutes)

\section{Duration \\ 60 seconds}

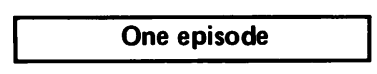

One episode

Fig 2 Example of how frequency and duration of episodes of negative vocalisations were determined. Two or more events which are separated from each other by five minutes or less are regarded as one episode.

two rules any episode lasting 30 seconds or less was excluded; and episodes that occurred when the parent was out of the house were excluded. Thus with the first cluster of events shown in fig 2 the four negative vocalisation events that were recorded during the first five minutes and 20 seconds would count as one episode lasting 105 seconds.

The only rule applied to the unreduced data reported in the diaries was the first, concerning the grouping of two events separated by five minutes or less. Because there are two categories in the diaries (cry and fuss) which could be used to represent negative vocalisations, it was interesting to know whether the overall duration of negative vocalisation was more strongly correlated with crying, fussing, or crying and fussing combined. Consequently the category 'cry and fuss' was defined as a composite of all crying and fussing episodes. Its duration was the arithmetic sum of the duration of all episodes of both crying and fussing on the diary. The frequency of episodes was calculated from the arithmetic sum of all the episodes of crying and fussing on the diary, but adjacent episodes were classed as one.

The resulting transcripts and diaries constituted the reduced sets of data giving the duration (minutes in 24 hours) and frequency (episodes in 24 hours) of negative vocalisations from the tape recordings and crying, fussing, or both, from the diaries. From the second rule (that defined duration on tape recordings) it was apparent that the durations of the episodes of negative vocalisations that were recorded were much less than those recorded in the diaries. If parents associated negative vocalisations equally with crying and fussing symbols, the correlations of duration of episodes recorded on the tape with crying and fussing recorded in the diary should have been similar. On the other hand, if parents associated negative vocalisations more with crying than with fussing symbols in the diary, the correla- tion should have been stronger with cry than with fuss, or with the combination. The frequency only refers to clusters of negative vocalisations regardless of the duration of particular negative vocalisations within the cluster. Consequently, the only useful comparison for frequency is between the number of combined crying and fussing episodes recorded in the diary and the number of negative vocalisation episodes on the tape recording.

As indices of how diary recordings represent episodes of negative vocalisations, three comparisons were made. Firstly, Pearson product moment correlations between frequency and duration measures from diary and tape recording methods were calculated for the reduced sets of data. Secondly, as an index of the completeness of the parents' recording the reduced sets of data were compared to determine the total duration and frequency of episodes missed by the diary records.

To work out differences in individual interpretations of the symbols for 'cry' and 'fuss' the diary records of episodes of crying and fussing that corresponded in time with tape recorded episodes of negative vocalisations were used to derive measures separately for cry and fuss symbols of the average duration of negative vocalisation events, the number of negative vocalisation events each minute, the total duration of negative vocalisations each minute, and the cry:fuss ratio of the total duration of negative vocalisations each minute.

USE OF THE DIARY IN A SAMPLE OF THE GENERAL POPULATION

A slightly modified version of the diary was used in a large prospective study to determine the causes of overweight in infants. ${ }^{9} 18$ Normal subjects were recruited from the neonatal nursery of a large general hospital associated with the university. ${ }^{9}$ Diaries and instructions for their use were given to the parents at home when the baby was 6 weeks old. 
The diaries were kept for seven days and then returned in a stamped, addressed envelope. If they were not received within two weeks the parents were telephoned to remind them.

\section{Results}

COMPARISON OF TAPE RECORDINGS AND DIARIES Satisfactory legible reports were obtained from all the parents. Most said that they had filled in the diary every two to four hours, usually during a routine activity such as feeding or nappy changing. Technically adequate tape recordings were obtained from all subjects.

Table 1 shows the duration and frequency of episodes of crying, fussing, or crying and fussing combined, from the diaries and negative vocalisations from the tape recordings. The combination of clusters of negative vocalisations into episodes on the tape recording with a mean frequency of 10.5 episodes in 24 hours was comparable with the number of combined crying and fussing episodes recorded in the diaries (mean 9.5 episodes in 24 hours). As expected the mean total duration of combined crying and fussing recorded in the diary (125 minutes in 24 hours) was much greater than the total duration of recorded negative vocalisation episodes on the tape ( 29 minutes in 24 hours). This was partly due to the more detailed recording of the intermittent sounds and pauses on the tape recording. In the diaries crying accounted for $53 \%$ of the frequency but only $43 \%$ of the duration of the total amount of crying and fussing.

Table 2 shows the correlations of the frequency and duration of crying and fussing episodes recorded in the diaries with the negative vocalisation episodes recorded on the tapes. The correlation between frequency of combined crying and fussing episodes and negative vocalisation episodes was moderately strong $(r=+0.64, p=0.03)$. One diary was much less accurate than the other nine because three negative
Table 2 Correlation of frequency and duration of episodes of crying and fussing reported in diaries with negative vocalisations on tape recording in 10 infants

\begin{tabular}{llc}
\hline $\begin{array}{l}\text { Episodes reported in } \\
\text { diary }\end{array}$ & \multicolumn{2}{l}{$\begin{array}{l}\text { Correlation with episodes of negative } \\
\text { vocalisations recorded on tape recorder }\end{array}$} \\
\cline { 2 - 3 } & $r$ value & $p$ value \\
\hline $\begin{array}{l}\text { Frequency: } \\
\text { Crying and fussing }\end{array}$ & $+0.64(+0.85)$ & $0.03(0.002)$ \\
$\begin{array}{l}\text { Duration: } \\
\text { Crying alone }\end{array}$ & $+0.67(+0.90)$ & $0.02(0.001)$ \\
Fussing alone & $-0.01(-0.26)$ & $0.44(0.26)$ \\
Crying and fussing & $+0.45(+0.41)$ & $0.09(0.14)$ \\
\hline
\end{tabular}

Figures in parentheses are calculated from nine diaries after other had been omitted.

vocalisation episodes that had been recorded on the tape had been omitted from the diary, and three other negative vocalisation episodes on the tape had been amalgamated into one crying episode on the diary. Both inaccuracies reduce considerably the frequency count for this diary and significantly affect the correlation for this small group. The strength of the association for frequency between recording methods for the other nine subjects is strong $(r=+0.85, p=0.002)$. The correlation between diaries and tape recordings for duration measures was best for crying alone and negative vocalisations $(r=+0.67, p=0.02)$; this comparison provided a strong correlation when the same nine diaries only were considered $(r=+0.90, p=0.001)$. There was no correlation of fussing alone with negative vocalisations, and this diminished the correlation for combined crying and fussing with negative vocalisations.

\section{TAPE RECORDED EPISODES NOT RECORDED IN THE} DIARIES

The 10 diaries were compared individually with their corresponding tape recorded episodes that had not been noted as either 'crying' or 'fussing' in the

Table 1 Comparison between diary recording and tape recording of frequency and duration of episodes of crying and fussing in 10 infants

\begin{tabular}{|c|c|c|c|c|}
\hline & \multicolumn{3}{|c|}{ Episodes reported in diary } & \multirow{2}{*}{$\begin{array}{l}\text { Episodes recorded } \\
\text { on tape recorder: } \\
\text { negative } \\
\text { vocalisations }\end{array}$} \\
\hline & Crying & Fussing & Crying and fussing & \\
\hline \multirow{2}{*}{\multicolumn{5}{|c|}{$\begin{array}{l}\text { Frequency: } \\
\text { Mean (SD) No of episodes }\end{array}$}} \\
\hline & & $5 \cdot 1(2 \cdot 3)$ & $9.5(3.0)$ & $10 \cdot 5(2 \cdot 3)$ \\
\hline Range & $1-10$ & $1-10$ & $4-14$ & $7-14$ \\
\hline Duration: & & & & \\
\hline $\begin{array}{l}\text { Mean (SD) No of minutes } \\
\text { in } 24 \text { hours }\end{array}$ & $53 \cdot 3(33 \cdot 9)$ & $71 \cdot 8(44 \cdot 9)$ & $125 \cdot 0(48 \cdot 1)$ & $28.9(14 \cdot 6)$ \\
\hline Range & $10-103$ & $10-170$ & $40-200$ & $11.9-57.9$ \\
\hline
\end{tabular}


diaries tabulated. Parents missed an average of $20 \%$ of the total duration of negative vocalisation episodes and $14 \%$ of the total number of episodes. Missed episodes were not more common during the night.

DIFFERENCES IN THE USE OF SYMBOLS FOR CRYING AND FUSSING

To characterise the use of the symbols we only compared those episodes that were recorded both in the diary and on the tape. From the definition of fussing that had been given to the parents we expected that the parents would be more likely to use a cry symbol to describe clusters in which the average duration of the negative vocalisation events was longer and the number of negative vocalisations more frequent, while the fuss symbol would be used for clusters with shorter and less frequent vocalisations.

There were large differences among parents when using these symbols, and one parent did not use the fuss symbol at all. Table 3 shows that the number of negative vocalisation events in clusters designated 'cry' were more frequent $(0.67$ and 0.25 events a minute, respectively) but not longer (each event lasting 29 and 28 seconds, respectively) than those designated 'fuss'. Consequently each minute of 'crying' represented more total seconds of negative vocalising than 'fussing' $(17.3$ and 8.7 seconds for each minute, respectively). Individual subjects' cry:fuss ratios indicated that seven of the nine parents used 'cry' to designate more negative

Table 3 Characteristics of negative vocalisations on tape recording referred to in diaries as 'cry' and 'fuss' in nine infants*: values are expressed as median (range)

\begin{tabular}{lr}
\hline & Cry \\
\hline Duration of negative vocalisation event (seconds) & $29(13-47)$ \\
Frequency of negative vocalisation events/minute of diary recording & $0 \cdot 67(0 \cdot 32-2 \cdot 8)$ \\
Duration of negative vocalisation/minute of diary recording (seconds) & $0 \cdot 25(0 \cdot 09-1 \cdot 20)$ \\
Cry:fuss ratio of total duration of negative vocalisation/minute of diary recording & $\begin{array}{c}17 \cdot 33(4 \cdot 2-60 \cdot 0) \\
8 \cdot 67(2 \cdot 43-48 \cdot 25)\end{array}$ \\
\hline
\end{tabular}

*One parent did not use the 'fuss' symbol and has been omitted.

Table 4 Characteristics of the mothers to whom diaries were sent, and their infants

\begin{tabular}{|c|c|c|c|c|}
\hline & $\begin{array}{l}\text { Diary not } \\
\text { returned } \\
(n=35)\end{array}$ & $\begin{array}{l}\text { Diary } \\
\text { incomplete } \\
\text { or illegible } \\
(n=10)\end{array}$ & $\begin{array}{l}\text { Diary } \\
\text { completed } \\
(n=374)\end{array}$ & $\begin{array}{l}p \\
\text { value }^{*}\end{array}$ \\
\hline \multicolumn{5}{|l|}{ Maternal characteristics: } \\
\hline Mean age (years) & 28 & 31 & 28 & NS \\
\hline Marital state (\% single) & 6 & 0 & 3 & NS \\
\hline Nationality $(\%)$ : & & & & $0 \cdot 04$ \\
\hline \multicolumn{5}{|l|}{ Anglo-Canadian, United States, } \\
\hline United Kingdom & 26 & 20 & 48 & \\
\hline French Canadian, France & 26 & 0 & 14 & \\
\hline Other European & 8 & 10 & 9 & \\
\hline Mediterranean & 14 & 30 & 11 & \\
\hline Other & 26 & 40 & 18 & \\
\hline \multicolumn{4}{|l|}{ Type of feeding at birth (\%): } & $0 \cdot 02$ \\
\hline Formula & 40 & 40 & 16 & \\
\hline Mixed & 14 & 20 & 16 & \\
\hline \multicolumn{4}{|l|}{ Type of feeding at 6 weeks (\%): } & NS \\
\hline Breast & 25 & 20 & 36 & \\
\hline Formula & 53 & 50 & 36 & \\
\hline Breast plus $\geqslant$ one bottle & 10 & 30 & 17 & \\
\hline Whole cows' milk & 3 & 0 & 2 & \\
\hline Mixed & 9 & 0 & 9 & \\
\hline \multicolumn{5}{|l|}{ Characteristics of infants: } \\
\hline Sex (\% male) & 54 & 50 & 55 & NS \\
\hline Mean birth order & 1.8 & $2 \cdot 4$ & $1 \cdot 6$ & $0 \cdot 01$ \\
\hline \multicolumn{5}{|l|}{ Mean infant temperament questionnaire } \\
\hline score $^{918}$ & $16 \cdot 0$ & $14 \cdot 3$ & $16 \cdot 7$ & NS \\
\hline
\end{tabular}

${ }^{*}$ Difference between complete diaries and those not completed or not returned ( $\chi^{2}$ or Student's unpaired $t$ test). 
vocalisation a minute than 'fuss' $(1.6$ to 25.4 times more) but the other two did not. Therefore, though there was a tendency for clusters of crying to represent a larger quantity of recorded negative vocalisation, the considerable variation between subjects suggested a wide range of individual recording styles.

USE OF THE DIARY IN A SAMPLE OF THE GENERAL POPULATION

Of the 409 eligible parents, diaries were not received from 35 either because they did not complete them $(n=10)$, or because they said they did but failed to return them $(n=25)$, equalling a response rate of $92 \%$. Of the 384 diaries recovered, 10 were incomplete or illegible, leaving $91 \%$ for analysis.

Table 4 shows the characteristics of the families in each group. Those who did not return them or who did not complete them correctly were similar. The mothers tended to be in a lower socioeconomic group and of Mediterranean or non-European origin, and they were more likely to choose formula feeding at birth. The infants tended not to be the first born. The only additional difference when comparing mothers whose diaries were returned but incomplete with those returned and complete was that they were older ( 31 and 28 years, respectively).

\section{Discussion}

Parents' records of infant behaviour patterns are useful in that they are inexpensive and large numbers of infants can be observed over long periods of time. For clinical and epidemiological purposes they are probably the only reasonable way of studying crying patterns, as these patterns vary from day to day and change significantly during the first three months of life, ${ }^{1-3}$ and multiple recordings of many infants are needed to reduce the variability due to sampling error inherent in small numbers of observations. With a less variable measure of crying, clinicians may be able to determine what factors if any predispose to crying ${ }^{18}$ and how specific interventions may affect them. ${ }^{19}$ We typically record only duration and frequency of episodes but it is these that are of interest to clinicians, and diaries will only help if they can be shown to be a reasonably accurate measure of these.

Our results suggest that diaries provide useful short term recordings of the vocal component of crying. The duration of two and one-quarter hours of combined crying and fussing behaviour recorded by diary is similar to previous reports for infants of this age. ${ }^{1-3}$ This represented only 30 minutes of negative vocalisations, but this is probably because parents also perceive infants as being distressed on the basis of motor behaviours when they are not crying and the tape recorded only the vocalisations. The moderate correlations with negative vocalisations for frequency of combined crying and fussing episodes and for duration of crying were satisfactory for the whole group. If the single poor diary is indeed atypical then the correlations between these measures may be stronger. These correlations were expected to be conservative estimates because of the isolation by audiotape of vocal aspects of crying, the differences in degree of detail between recording methods, dependence on recall, and the emphasis on simplicity and ease of use of the diaries. In studies limited to well motivated parents who would be required to make more frequent recordings in the diaries, better correlations might be obtained.

The strength of the associations was also affected by the reporting styles of individual parents. Our methods for grouping the data obtained from the tape recordings imposed a degree of consistency on the recordings, but were perhaps not sensitive enough to account for the widely varying styles. For example a 'ten minute rule' would have improved the frequency correlations but reduced the sensitivity of the measures to reflect differences between individuals. In this sense the use of the 'five minute rule' provides a more conservative estimate of the accuracy of the diaries.

There have been many reports of crying patterns ${ }^{20}$ but fussing has received less attention. ${ }^{21}{ }_{22}$ We included it in this study at the request of parents who wanted a category between 'crying' and 'awake and content'. As it is less intense than crying it might have been expected to be associated with shorter and less frequent negative vocalisation events. While the total duration of negative vocalisation was less, this was because of a decreased number of (rather than shorter) vocal events. There was, however, a great deal of variability among subjects concerning both the frequency and duration of events included in a crying or fussing episode. The fuss symbol was probably used by some parents to indicate agitated motor behaviour not accompanied by much sound. Differences in recording styles, the shorter duration of vocalisation associated with 'fussing' and the use of the fuss symbol to refer to primarily motor behaviour may explain the absence of a correlation between diary recording of 'fussing' and tape recording of negative vocalisations. This does not imply that the 'fuss' symbol was used less accurately but that the behaviour was different. On the contrary, diaries may well be more accurate than tape recordings for studying patterns of distress, since tape recordings capture only the vocal components of distress behaviour.

The usefulness of the diaries depends not only on 
what and how accurately they record, but on how acceptable they are to parents. Our results suggest that though we obtained appropriate data which we could interpret from $90 \%$ of the subjects this may have represented a biased sample in that families of lower socioeconomic groups, ethnic minorities, large families, older mothers, and children who were formula fed from birth may be under represented.

Our findings have several implications. First, the extent of agreement between diary recording and tape recording may have been favourably biased by the presence of the recorder, the novelty of the procedure, and the short duration of the recording period. On the other hand, the lack of interference (filling in the diary when convenient), the simplicity of instructions, and the lack of a formal practice session may have resulted in less than optimal recordings. In particular applications more accurate recordings could probably be achieved-for example, in small studies with well motivated parents.

Secondly, the differences in the use of the 'cry' and 'fuss' symbols indicate that (contrary to common practice) the two concepts should not be considered synonymous. Some papers about crying and colic use the terms interchangeably. ${ }^{12}$ They are often used to indicate degrees of severity of distress, ${ }^{21} 22$ but some use fussing to indicate 'unexplained' crying. ${ }^{6}$ Our results show that the symbols were not used interchangeably by parents and that other behavioural features may have played a part in the designation of fuss. As a result diaries with a symbol for cry only may not be recording an important sign of infant distress, whereas diaries that refer to fussing only may not capture a marker of severity of distress distinguishable by the parents. ${ }^{21}$

We thank Mr B Van Barneveld and Mr CE Beachell of the Technical Research Division, National Film Board of Canada, Montreal for their help in designing and building the recording system. We also thank Ms Madeleine Ranger and Ms Maria Szasz for secretarial assistance and Dr Howard Foye for helpful comments on the manuscript. The study was supported by grants from the National Health Research and Development Program, Health and Welfare Canada, and the WT Grant Foundation.

\section{References}

1 Brazelton TB. Crying in infancy. Pediatrics 1962;29:579-88.

2 Wessel MA, Cobb JC, Jackson EB, et al. Paroxysmal fussing in infancy, sometimes called 'colic'. Pediatrics 1954;14:421-34.
3 Aldrich CA, Sung C, Knop C. The crying of newly born babies III. The early period at home. J Pediatr 1946;28:428-35.

${ }^{4}$ Bernal J. Crying during the first 10 days of life, and maternal responses. Dev Med Child Neurol 1972;14:362-72.

5 Rebelsky F, Black R. Crying in infancy. J Genet Psychol 1972;121:49-57.

6 Emde RN, Gaensbauer TJ, Harmon R. Emotional expression in infancy; a biobehavioural study. New York: International Universities Press, 1976;80-5.

7 Bloom K. McDowell EE. Time-sampling caretaker and infant behaviours in the first five weeks of life. J Psychol 1972;80: 111-20.

* Green LW. Manual for scoring socioeconomic status for research in health behaviour. Public Health Rep 1970;85: 815-27.

9 Kramer MS, Barr RG, Leduc DG, et al. Determinants of weight and adiposity in the first year of life. J Pediatr 1985;106:10-14.

${ }^{10}$ Chan M, Lennenberg E, Rebelsky F. Apparatus for reducing play-back time of tape-recorded intermittent vocalization. Monogr Soc Res Child Dev 1964;29:127-30.

"Sosken WF, John VP. The study of spontaneous talk. In: Barker RG, ed. The stream of behaviour. New York: AppletonCentury-Crofts, 1963:228-81.

12 Johnson SM, Christensen A, Bellamy GT. Evaluation of family intervention through unobtrusive audio recordings: experiences in 'bugging' children. J Appl Behav Anal 1976;9:213-19.

13 Reisinger JJ, Ora JP. Parent-child clinic and home interaction during toddler management training. Behaviour Therapy 1977; 8:771-86.

${ }^{14}$ Purcell K, Brady K. Adaptation to the invasion of privacy: monitoring behaviour with a miniature radio transmitter. Merrill Palmer Quarterly 1966;12:242-54.

15 Hoshiko M, Holloway G. Radio telemetry for the monitoring of verbal behaviour. J Speech Hear Disord 1968;33:48-50.

${ }^{16}$ Nordquist MV. A method for recording verbal behaviour in free-play settings. J Appl Behav Anal 1971;4:327-31.

17 Hughes M, Carmichael H, Pinkerton G, et al. Recording children's conversations at home and at nursery school: A technique and some methodological considerations. J Child Psychol Psychiatry 1979;20:225-32.

18 Barr RG, Kramer MS, Pless IB, et al. Feeding and temperament predispose to cry/fuss behaviour at 6 weeks. Am J Dis Child 1983;13:541.

${ }^{19}$ Hunziker UA, Barr RG. Parent carrying reduces infant crying behaviour: a randomized controlled trial. Pediatrics 1986; 77:641-8.

${ }^{20}$ Lester BM, Zeskind PS. A biobehavioural perspective on crying in early infancy. In: Fitzgerald HE, Lester BM, Yogman MW, eds. Theory and research in behavioural pediatrics, vol 1. New York: Plenum Press, 1982:133-80.

21 Petrovich-Bartell N, Cowan N, Morse PA. Mothers' perceptions of infant distress vocalizations. Journal of Speech and Hearing Research 1982;25:371-6.

22 Stark RE, Rose SN, McLagen M. Features of infant sounds: the first eight weeks of life. Journal of Child Language 1975;2:205-21.

Correspondence and requests for reprints to Dr RG Barr, Montreal Children's Hospital, 2300 Tupper Street, Montreal, PQ, Canada $\mathrm{H} 3 \mathrm{H} 1 \mathrm{P} 3$, from whom copies of the diary and instructions for its use may be obtained.

Accepted 13 July 1987 